\title{
Mouse Models and Techniques for the Isolation of the Diabetic Endothelium
}

\author{
April L. Darrow, ${ }^{1,2,3}$ J. Gregory Maresh, ${ }^{1,3}$ and Ralph V. Shohet ${ }^{1,3}$ \\ ${ }^{1}$ Center for Cardiovascular Research, University of Hawaii John A. Burns School of Medicine, Honolulu, HI 96813, USA \\ ${ }^{2}$ Department of Cell and Molecular Biology, University of Hawaii John A. Burns School of Medicine, Honolulu, HI 96813, USA \\ ${ }^{3}$ Department of Medicine, University of Hawaii John A. Burns School of Medicine, 651 Ilalo Street, Honolulu, HI 96813, USA
}

Correspondence should be addressed to Ralph V. Shohet; shohet@hawaii.edu

Received 1 April 2013; Accepted 17 April 2013

Academic Editors: E. Spinedi and N. Tentolouris

Copyright (c) 2013 April L. Darrow et al. This is an open access article distributed under the Creative Commons Attribution License, which permits unrestricted use, distribution, and reproduction in any medium, provided the original work is properly cited.

Understanding the molecular mechanisms underlying diabetic endothelial dysfunction is necessary in order to improve the cardiovascular health of diabetic patients. Previously, we described an in vivo, murine model of insulin resistance induced by feeding a high-fat diet (HFD) whereby the endothelium may be isolated by fluorescence-activated cell sorting (FACS) based on Tie2-GFP expression and cell-surface staining. Here, we apply this model to two new strains of mice, ScN/Tie2-GFP and ApoE(-/-)/Tie2-GFP, and describe their metabolic responses and endothelial isolation. ScN/Tie2-GFP mice, which lack a functional toll-like receptor 4 (TLR4), display lower fasting glucose and insulin levels and improved glucose tolerance compared to Tie2-GFP mice, suggesting that TLR4 deficiency decreases susceptibility to the development of insulin resistance. ApoE(-/-)/Tie2-GFP mice display elevated glucose and cholesterol levels versus Tie2-GFP mice. Endothelial isolation by FACS achieves a pure population of endothelial cells that retain GFP fluorescence and endothelial functions. Transcriptional analysis of the aortic and muscle endothelium isolated from ApoE(-/-)/Tie2-GFP mice reveals a reduced endothelial response to HFD compared to Tie2-GFP mice, perhaps resulting from preexisting endothelial dysfunction in the hypercholesterolemic state. These mouse models and endothelial isolation techniques are valuable for assessing diabetic endothelial dysfunction and vascular responses in vivo.

\section{Introduction}

Vascular complications are the main causes of morbidity and mortality associated with diabetes. Diabetics have a $2-4-$ fold increased risk for developing cardiovascular disease [1]. Progressive degeneration of microvascular beds is a major contributing factor to many complications of diabetes including retinopathy, nephropathy, and neuropathy. Macrovascular complications associated with diabetes include coronary heart disease, stroke, and peripheral vascular disease. The relationship between diabetes and vascular complications emphasizes the importance of understanding the mechanisms underlying this association.

The increased risk of cardiovascular disease observed in diabetes is primarily due to a damaged or dysfunctional endothelium. In the diabetic state, numerous inflammatory, hormonal, and metabolic influences impinge upon the endothelium and alter its function. Elevated glucose and fatty acids lead to endothelial nitric oxide synthase (eNOS) uncoupling [2]. This in turn leads to reduced nitric oxide bioavailability and generation of reactive nitrogen and oxygen species as well as increased glycation of proteins and lipids [3-5]. Pathological levels of hormones and cytokines in the diabetic state alter endothelial signaling pathways promoting inflammation and atherogenesis and impairing vasoregulation and vascular hemostasis $[6,7]$. Endothelial dysfunction precedes symptomatic vascular disease and is often detected before structural changes in the vascular wall [2]. A deeper understanding of the mechanisms underlying the endothelial response to diabetes should lead to new therapeutic interventions to inhibit these changes before they progress to vascular disease. It may also identify useful biomarkers of diabetic vasculopathy. 
Endothelial isolation has been difficult, in part due to the lack of specific markers available for the endothelium. Column purification techniques often lead to contamination by other cell types. A freeze-fracture technique [8] and scraping of the endothelium off the vessel wall [9] usually do not achieve pure populations of endothelial cells and may cause damage leading to RNA degradation. These techniques may be acceptable if further selection is possible, such as altering cell culture conditions to eliminate contaminating cell types. However, in vitro responses of endothelial cells are highly dependent on the choice of growth medium and flow conditions [10]. In vitro studies are further complicated by the altered expression of endothelial cell markers and function commonly observed in both primary isolates and immortalized cultures [11]. Most importantly, monoculture of endothelial cells is a terrifically artificial environment lacking the hemodynamic stimuli, intercellular interactions, and hormonal influences of the intact, perfused, in vivo blood vessel. Therefore, assessment of the endothelial response to diabetes is optimally obtained with an in vivo murine model of diabetes accompanied by rapid isolation of pure populations of endothelial cells.

We have previously described a high-fat diet-induced model of insulin resistance using Tie2-GFP mice wherein the endothelium can be reliably isolated by fluorescence-activated cell sorting based on Tie2-driven GFP expression and cell-surface staining for endothelial markers [12]. Here we have applied this high-fat model to two new strains of mice, ScN/Tie2-GFP and ApoE(-/-)/Tie2-GFP, created by interbreeding with Tie2-GFP mice. ScN/Tie2-GFP lack a functional toll-like receptor 4 (TLR4), which serves an important role in innate immunity and is the principal sensor of LPS [13]. TLR4 has also been implicated in promoting vascular insulin resistance by binding free fatty acids followed by subsequent activation of inflammatory pathways [14]. $A p o E(-/-)$ mice lack the lipid carrier, apolipoprotein E, and consequently display hypercholesterolemia and increased susceptibility to the development of atherosclerosis. The crossing of TLR4- and APOE-deficient mice with Tie2-GFP mice allows the isolation of their endothelium in order to elucidate the molecular biology underlying these observed vascular phenotypes. Here we characterize the metabolic profiles of both strains after feeding a high-fat diet and compare their endocrine responses to that of Tie2-GFP mice. We also provide a detailed description of our endothelial isolation technique and other important considerations when studying the diabetic vasculature.

\section{Methods}

2.1. Animals and Diet. Mice homozygous for the Tie2-green fluorescent protein (GFP) transgene (Tg(TIE2GFP)287Sato, stock number 003658 Jackson Laboratories (Bar Harbor, $\mathrm{ME})$ ) were bred for these experiments. Tie2-GFP mice were interbred with BL/6 ApoE(-/-) (strain name B6.129P2-Apo $E^{\mathrm{tmlUnc}} / \mathrm{J}$ (stock number 002052)) and genetically selected to obtain $A p o E(-/-) / T i e 2-G F P$ mice on an approximately $1: 1$ mixed genetic background of C57BL/6 and FVB/N. Tie2-GFP mice were also crossed with $\mathrm{BL} / 10 \mathrm{ScN}$ (strain name C57BL/10ScNJ (stock number 003752)) and genetically selected to obtain ScN/Tie2-GFP mice on an approximately $1: 1$ mixed genetic background of C57BL/10 and FVB/N. For simplicity, ScN/Tie2-GFP and ApoE(-/-)/Tie2-GFP mice will be referred to as ScN/GFP and $A p o E(-/-) / G F P$, respectively. Beginning at 8 weeks of age, male mice were allowed to feed ad libitum on a high-fat diet (HFD) containing 60\% fat calories (BioServ, Frenchtown, NJ, cat. number S3282) for a period up to 8 weeks. Littermates fed a normal chow diet containing $12 \%$ fat calories (LabDiet, St. Louis, MO, cat. number 5001) served as controls. All procedures were approved by the Institutional Animal Care and Use Committee of the University of Hawaii.

2.2. Measurement of Metabolic Characteristics. After 2, 4, 6 , and 8 weeks on their respective diets, glucose levels were determined by glucometry of the tail blood following an overnight fast (OneTouch Ultra, Lifescan, Milpitas, CA, USA). A glucose tolerance test (GTT) was performed after 6 weeks on the diet regimen. Glucose $(1 \mathrm{mg} / \mathrm{g}$ of body weight) was administered i.p. following an overnight fast. Glucometry of the tail blood was performed prior to glucose injection and every 20 minutes afterwards for $2 \mathrm{hrs}$. The area under the curve (AUC) was determined using the statistical software in Graphpad. After 8 weeks of HFD, insulin levels were measured in serum from overnight-fasted mice using a Mercodia Mouse Insulin ELISA kit (Uppsala, Sweden, cat. number 10-1149-01). Total cholesterol in the sera of overnightfasted HFD-fed and chow-fed ApoE(-/-)/Tie2-GFP mice and both parental strains were measured by ELISA performed according to manufacturer's instructions (Cayman Chemical, Ann Arbor, MI, USA, cat. number 10007640).

2.3. Endothelial Isolation. Animals were sacrificed by $\mathrm{CO}_{2}$ asphyxiation and perfused with ice cold PBS. Aortae were dissected from the aortic root to the iliac bifurcation. Leg muscles consisting of the plantaris, gastrocnemius, and biceps femoris (which are readily dissected as a single group) were excised. Tissues were placed in cold PBS, and adherent fat was removed. The aortic and skeletal muscle tissues from 3 animals were each pooled, minced into $1 \mathrm{~mm}$ fragments, and dispersed in PBS with $100 \mathrm{mMCaCl}_{2}$ and $\mathrm{MgCl}_{2}$ containing $5 \mathrm{mg} / \mathrm{mL}$ collagenase type 2 (Worthington Biochemical, Lakewood, NJ, cat. number LS004174), $2 \mathrm{mg} / \mathrm{mL}$ glucose, and $30 \mathrm{U} / \mathrm{mL}$ DNAse I (Worthington Biochemical, cat. number LS006331) under constant agitation (180 rpm at $\left.37^{\circ} \mathrm{C}\right)$. Aortae were collagenolytically digested for $40 \mathrm{~min}$, while the muscle was digested for $1 \mathrm{~h}$, with mechanical dissociation obtained by triturating every $10 \mathrm{~min}$. Enzyme activity was stopped by the addition of a $10 \%$ solution of FBS in PBS. Cells were pelleted by centrifugation ( $5 \mathrm{~min}, 1000 \mathrm{rpm}, 4^{\circ} \mathrm{C}$ ), aspirated, resuspended in PBS, and filtered through a $40 \mu \mathrm{m}$ cell strainer (BD Biosciences, San Jose, CA, USA, cat. number 352340). Red blood cells were lysed by resuspension in $1 \mathrm{~mL}$ RBC Lysis Solution (Applichem, St. Louis, MO, USA, cat. number A4617) overlaid on $4.5 \mathrm{~mL}$ FBS followed by centrifugation. In each experiment, pooled cells from 3 experimental and 3 control mice were collected for each tissue. 
Suspensions of collagenolytically separated cells were incubated with anti-mouse CD16/32 (1:500) for 5 min to prevent Fc binding, followed by phycoerythrin- (PE-) conjugated anti-mouse CD31 (1:200) for 25 minutes on ice (eBiosciences, San Diego, CA, cat. numbers 14-0161 and 12-0311). Cells were washed and resuspended in FACS buffer (PBS with $0.5 \mathrm{mM}$ EDTA, $30 \mathrm{U} / \mathrm{mL}$ DNAse, $3 \%$ FBS, and $2 \mathrm{mg} / \mathrm{mL}$ glucose). Immediately before sorting, the cell suspension was passed through a CellTrics $30 \mu \mathrm{m}$ filter (Partec, Swedesboro, NJ, USA). Endothelial cells positive for both GFP and phycoerythrin staining were isolated with a FACSAria (Becton Dickinson, Franklin Lakes, NJ, USA). Cells were sorted directly into TRIzol (Invitrogen, Carlsbad, CA, USA) for transcriptional analyses or into medium (Endothelial Cell Growth Medium MV with supplement mix, PromoCell, Heidelberg, Germany, cat. number C-22020) for subsequent culturing or cytospin preparations.

2.4. Matrigel Tube Formation and Acetylated-Low Density Lipoprotein (ac-LDL) Uptake Assays. GFP ${ }^{+}$endothelial cells from the skeletal muscle were isolated by FACS and sorted into tissue culture medium for fluorescence microscopy and functional assays to confirm their endothelial origin. Aliquots containing 1000 cells were deposited onto lysine-coated slides by centrifugation at $450 \mathrm{rpm}$ for 5 minutes with a Cytospin (Shandon). Cells were fixed in 10\% formalin for $30 \mathrm{~min}$ and mounted in DAPI-containing medium. Cells were viewed under the fluorescent microscope and images were collected with an Axiophot system (Zeiss, Oberkochen, Germany).

For tube formation assays, approximately 8,000 $\mathrm{GFP}^{+}$, sorted endothelial cells were plated per well in 48-well plates coated with Matrigel Basement Membrane Matrix (BD Biosciences, cat. number 354234) and allowed to grow in endothelial growth medium. After 5 days, tube formation was assessed. For ac-LDL uptake assays, the sorted endothelial cells were plated on Nunc Lab-Tek 8-well chamber slides (Thermo Scientific, Billerica, MA, USA, cat. number 154941) and incubated with $50 \mu \mathrm{g} / \mathrm{mL}$ Dil-Ac-LDL (Biomedical Technologies Inc., Stoughton, MA, USA, cat. number BT-902) for 4 hours, washed, fixed in $2 \%$ paraformaldehyde, stained with DAPI, and imaged using the Axiophot system (Zeiss).

2.5. Flow Cytometry Analysis of Peripheral Blood Mononuclear Cells (PBMCs). Approximately $200 \mu \mathrm{L}$ of blood was collected from the retro-orbital vein of chow- and HFD-fed mice after 8 weeks of feeding into EDTA-coated tubes. RBCs were lysed using a 1: 10 dilution of BD Pharm Lyse (cat. number 555899). Leukocytes were stained for $20 \mathrm{~min}$ at $4^{\circ} \mathrm{C}$ with $50 \mu \mathrm{L}$ of antibody cocktail containing $0.5 \mu \mathrm{L}$ each of PE-conjugated antimouse CD115 (eBiosciences, cat. number 12-1152), peridinin chlorophyll protein-cyanine 5.5- (PerCP-Cy5.5-) conjugated anti-CD11b (BD Biosciences, cat. number 550993), allophycocyanin-cyanine 7 (APC-Cy7) anti-CD45 (BD Biosciences, cat. number 557659), and PE-Cy7 anti-CD31 (eBiosciences, cat. number 25-0311) diluted in a 1:1 solution of Hanks: FACS staining buffer $(1.7 \%$ BSA, $0.02 \%$ mouse serum, $0.02 \%$ rabbit serum, and $0.02 \%$ human serum). After washing, samples were fixed for $20 \mathrm{~min}$ at RT in a 1:1 solution of Hanks: fixation buffer (Biolegend, San Diego, CA, USA, cat. number
420801). Flow cytometry was performed on a FACSAria, and $\mathrm{CD}_{4} 5^{+}$leukocytes, $\mathrm{CD} 45^{+} / \mathrm{CD} 11 \mathrm{~b}^{+}$myeloid cells, and $\mathrm{CD} 5^{+} / \mathrm{CD} 1 \mathrm{~b}^{+} / \mathrm{CD} 115^{+}$monocytes were analyzed for GFP signal using FlowJo software (Tree Star, Inc., Ashland, OR, USA).

2.6. Flow Cytometry Analysis of Endothelial Populations Stained for Monocyte Markers. Collagenolytically separated cell suspensions derived from aortic and muscle tissues as previously described were stained for $25 \mathrm{~min}$ at $4^{\circ} \mathrm{C}$ with Alexa Fluor ${ }^{\circledR} 647$ anti-mouse CD11b (eBiosciences, cat. number 51-0112), and flow cytometry was performed on a FACSAria. The sorting gates were established by initially gating for mononuclear cells based on forward scatter. This was followed by gating for GFP fluorescence, which was considered to be any signal in the FITC channel above that of an unstained, non-GFP sample. After applying the sorting gate for the $\mathrm{GFP}^{+}$endothelial cells, the number of $\mathrm{GFP}^{+} / \mathrm{CD} 1 \mathrm{~b}^{+}$events within that gate was analyzed using FlowJO software.

2.7. Microarray Analysis. Microarray analyses were performed to determine the transcriptional responses in aortic and skeletal muscle endothelium from $A p o E(-/-) / G F P$ mice exposed to high-fat diet for 4 weeks compared to ApoE(-/-)/GFP mice fed a chow diet. 10,000 endothelial cells positive for both GFP and phycoerythrin-CD31 staining were isolated with a FACSAria directly into TRIzol. RNA was purified with RNeasy columns (Qiagen, Valencia, CA, USA) to yield $<80 \mathrm{ng}$, which was then amplified using an Ambion Amino Allyl MessageAmp kit (Life Technologies, Carlsbad, CA, USA, cat. number AM1753) according to the manufacturer's protocol to produce approximately $100 \mu \mathrm{g}$ of aminoallyl modified cRNA. This was labeled with $\mathrm{Cy} 3$ and Cy5 CyDye Post-Labeling Reactive Dye Pack (GE Healthcare, Waukesha, WI, USA) according to the manufacturer's instructions. Following purification, 200 pmoles of Cy3 and Cy5 dye-labeled cRNA, as measured by NanoDrop 2000c spectrophotometer (Thermo Scientific), were combined and fragmented with Ambion 10X fragmentation reagents at $70^{\circ} \mathrm{C}$ for $15 \mathrm{~min}$. Yeast tRNA ( $4 \mu \mathrm{g})$, polyA RNA $(4 \mu \mathrm{g})$, mouse cot-1 DNA $(1 \mu \mathrm{g})$, and Slidehyb III hybridization buffer (Ambion) were added for a total sample volume of $35 \mu \mathrm{L}$. Triplicate experiments were performed for both tissues. For each of the biological replicate experiments, two array hybridizations were performed, each of which included a dye reversal. Samples were hybridized overnight to glass slides spotted with the Operon Murine V4 oligo set produced by the Duke University Microarray Core. Arrays were scanned using a Genepix 4000B system (Molecular Devices, Union City, CA, USA) and analyzed with Genepix and Acuity software.

Statistical analysis of microarray results was performed using the functions available within Acuity. Results were normalized using the ratio of medians method and filtered to exclude any exhibiting the following characteristics: a percentage of saturated pixels $>3$, a signal/noise ratio $<3$, a (regression ratio 635/532) ( $^{2}<0.6$, or a Genepix flag. Transcripts exhibiting upregulation (a $\log _{2}$ (fold change) $>0.75$ ) or downregulation $\left(\log _{2}(\right.$ fold change $\left.)<-0.75\right)$ were tabulated 
TABLE 1: Composition of high-fat diet (Bioserv S3282) and control diet (LabDiet 5001).

\begin{tabular}{lccc}
\hline $\begin{array}{l}\text { Nutritional } \\
\text { component }\end{array}$ & $\begin{array}{c}\text { Composition by } \\
\text { weight }(\%)\end{array}$ & $\begin{array}{c}\text { Calories } \\
(\mathrm{kcal} / \mathrm{g})\end{array}$ & \% Calories \\
\hline Fat & 36 & 3.2 & 59 \\
Carbohydrate & 35.7 & 1.4 & 26 \\
Protein & 20.5 & 0.8 & 15 \\
\hline Total & & 5.5 & \\
\hline Fat & 4.5 & 0.40 & 12 \\
Carbohydrate & 49.9 & 2.0 & 60 \\
Protein & 23.4 & 0.9 & 28 \\
\hline Total & & 3.3 & \\
\hline
\end{tabular}

for each tissue. The one sample $t$-test function within Acuity was then applied to the results to calculate $P$ values for each transcript.

\section{Results and Discussion}

3.1. Murine Model of Type II Diabetes. In order to provide a more authentic model of the pathophysiological response observed in the human population, we have chosen to use a nutritional model of type II diabetes induced by feeding a high-fat diet consisting of $60 \%$ fat calories. The compositions of the high-fat and chow diets are compared in Table 1. The high-fat diet contains nearly $60 \%$ of its calories from fat, while the normal chow diet derives $60 \%$ of its calories from carbohydrates and only $12 \%$ of its calories from fat (Table 1). The total caloric intake per gram is much greater in the HFD compared to the chow diet (Table 1). Therefore, mice consuming equal quantities of the diet receive more calories from the HFD than the chow diet, and this is further exacerbated by the hyperphagia induced by the HFD [15]. Studies have also shown that calories derived from fat are more diabetogenic than the same caloric intake from carbohydrates [16]. In humans, dietary fat intake has been linked to obesity, decreased insulin sensitivity, and progression to type II diabetes [17-19]. High-fat diets also raise LDL cholesterol and increase LDL particle size compared to low-fat diets in human subjects [20].

This diabetic model allows us to evaluate the endothelial response to the diabetic milieu as a whole without selecting for particular biochemical attributes of diabetes. However, this also means that individual responses of the endothelium cannot be definitively ascribed to one aspect of diabetes or another, such as those changes due to insulin resistance versus hyperglycemia versus weight gain, and so forth. However, we can try to assign causation based on our current understanding of endothelial cell biology and the effects of diabetes in other cell types. The use of knockout models, however, does allow us to determine differential vascular responses due to a specific gene deletion. Analysis of ScN/GFP and $A p o E(-/-) / G F P$ endothelial responses to this high-fat diet provides insight into the effect of TLR 4 and APOE deficiency.
3.2. Metabolic Characteristics of ScN/GFP Mice on a HighFat Diet Regimen. As we have previously described, Tie2GFP mice have accelerated weight gain and hyperglycemia by 2 weeks, marked hyperinsulinemia and impaired glucose tolerance by 6 weeks, and aortic vascular insulin resistance observed after 5 weeks of HF feeding [12]. ScN/GFP mice on chow diet have lower fasting glucose levels compared to Tie2GFP mice (Table 2). Over the time course of the feeding, the weights and fasting glucose levels of ScN/GFP mice increase compared to chow-fed controls (Table 2). Although elevated compared to chow-fed controls, the fasting glucose levels of ScN/GFP mice remain significantly lower than that of Tie2GFP mice even after 8 weeks of HFD (Table 2). Insulin levels of ScN/GFP mice are also much lower compared to Tie2-GFP mice and are not different from chow-fed controls (Figure 1(a)). Glucose tolerance testing of ScN/GFP mice after 6 weeks of HFD reveals a normal response to glucose challenge compared to Tie2-GFP HFD mice where glucose tolerance is impaired (Figures 1(b) and 1(c)).

Obese and type II diabetic patients display increased expression of TLR4 in their skeletal muscle, implicating its role in diabetic pathophysiology [21]. Following 8 weeks of high-fat diet, whole aorta lysates from C57BL/6 mice have been shown to display decreased phosphorylation of protein kinase B (AKT) and endothelial nitric oxide synthase (eNOS) after insulin stimulation, suggesting a state of vascular insulin resistance and impaired vasoregulation, which were not observed in TLR4(-/-) mice [14]. Our studies also suggest that TLR4 serves a role in the development of insulin resistance as its deficiency in ScN/GFP mice lowers glucose and insulin levels and improves glucose tolerance. The ability to isolate the endothelium from these mice allows molecular studies to elucidate the mechanisms underlying the role of TLR4 in vascular insulin resistance and endothelial dysfunction.

3.3. Metabolic Characteristics of ApoE(-/-)/GFP Mice on a High-Fat Diet Regimen. ApoE(-/-)/GFP mice also display increased weight gain after HFD feeding (Table 2). Unlike ScN/GFP mice, the fasting glucose levels of $A p o E(-/-) / G F P$ mice are elevated compared to Tie2-GFP mice (Table 2). Over the time course of the feeding, the fasting glucose levels of ApoE(-/-)/GFP mice on HFD increase slightly compared to chow-fed controls. ApoE(-/-)/BL/6 mice are hypercholesterolemic due to defective lipoprotein metabolism. We therefore assessed the total cholesterol levels in the sera of $A p o E(-/-) / G F P$ mice and found that they exhibit similar cholesterol levels to ApoE(-/-) mice on the C57BL/6 background. After 5 months of HF feeding, these levels doubled (Figure 2).

3.4. Choice of Endothelial Population. To assess macrovascular responses, we isolate the endothelium of the largest artery, the aorta. To assess microvascular responses, we isolate the leg muscle. The vasculature of the skeletal muscle is mostly composed of small arterioles and venules of capillary beds with some larger arteries and veins feeding into them. Therefore, the endothelial cells isolated from the muscle are a heterogeneous mixture of arterial, venular, and lymphatic 


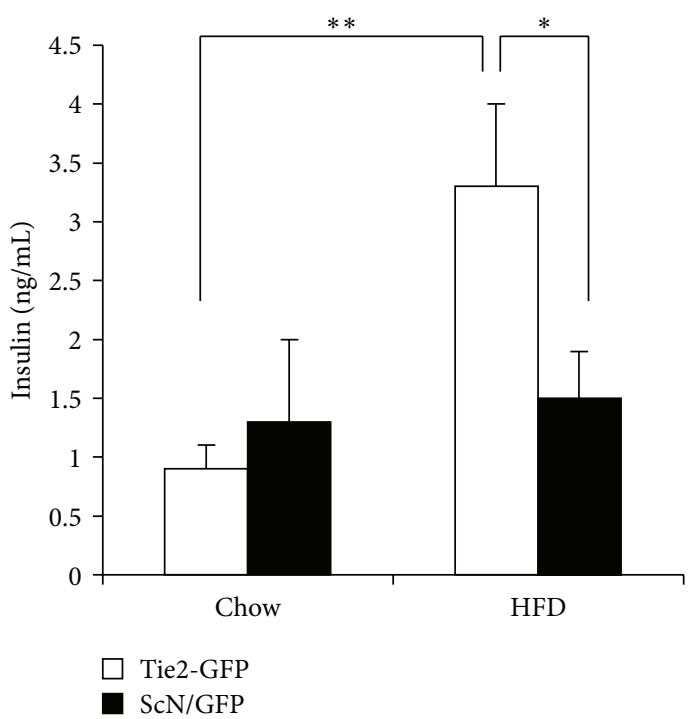

(a)

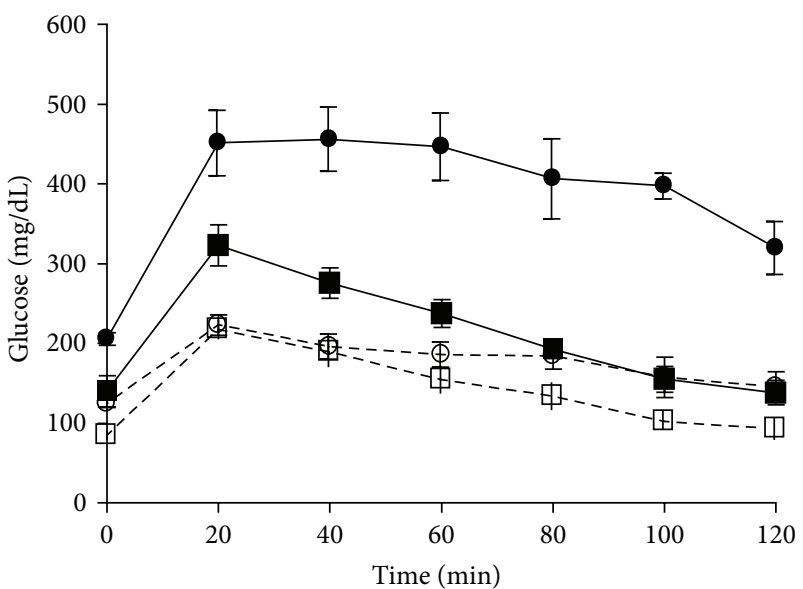

$\begin{array}{ll}-\Theta-\text { Tie2-GFP chow } & -\square-\text { ScN/GFP chow } \\ - & - \text { Tie2-GFP HFD }\end{array}$

(b)

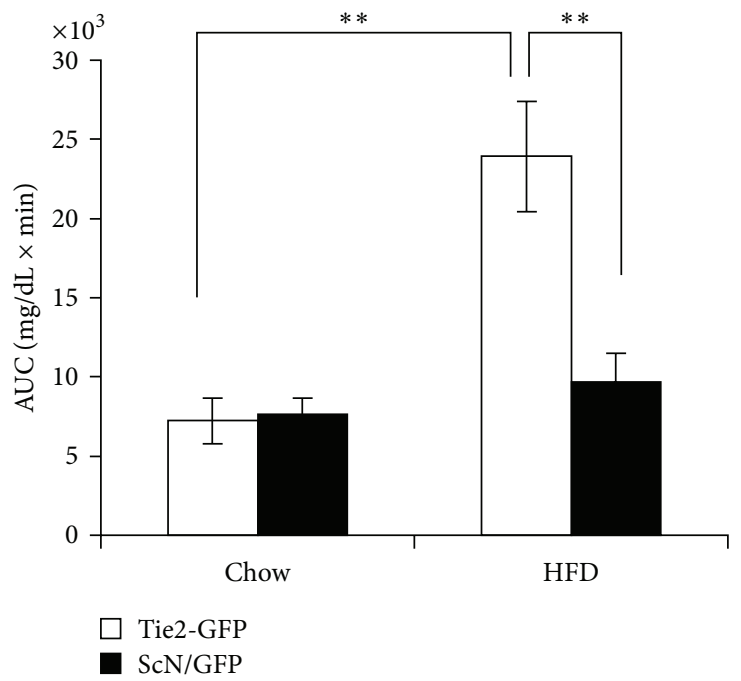

(c)

Figure 1: (a) Fasting insulin levels of ScN/GFP and Tie2-GFP mice after 8 weeks of HFD or chow diet $(n=3-9)$. (b) Following 6 weeks of HFD, glucose tolerance was determined by performing glucometry over a $2 \mathrm{~h}$ period after an intraperitoneal injection of glucose ( $1 \mathrm{mg} / \mathrm{g}$ ) following an overnight fast $(n=5-6)$. (c) Area under the curve of the glucose tolerance test. The data are presented as means \pm SE. ${ }^{*} P<0.05$ and ${ }^{* *} P \leq 0.01$.

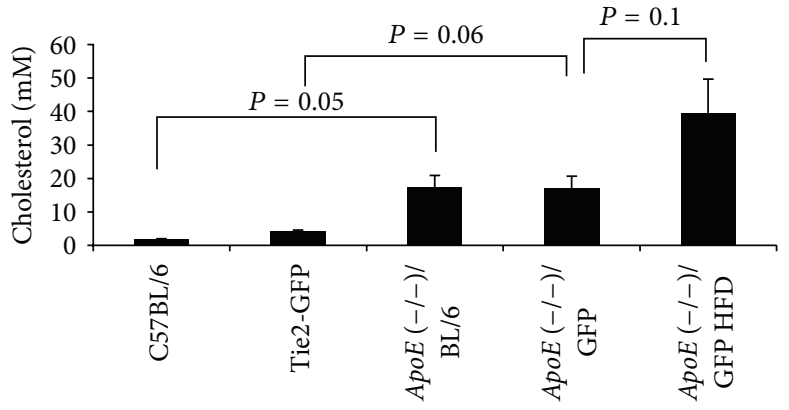

Figure 2: Total serum cholesterol levels of ApoE(-/-)/GFP mice on chow or HFD compared to that of the parental strains. Data is shown as mean \pm SE $(n=3)$. 
TABLE 2: Weights and fasting glucose levels of Tie2-GFP, ScN/GFP, and ApoE(-/-)/GFP mice receiving a high-fat diet versus chow diet.

\begin{tabular}{|c|c|c|c|c|c|c|}
\hline \multirow{2}{*}{$\begin{array}{l}\text { Weeks } \\
\text { on diet }\end{array}$} & \multicolumn{2}{|c|}{ Tie2-GFP } & \multicolumn{2}{|c|}{ ScN/GFP } & \multicolumn{2}{|c|}{$A p o E(-/-) / G F P$} \\
\hline & Chow & HFD & Chow & HFD & Chow & HFD \\
\hline \multicolumn{7}{|c|}{ Weight (g) } \\
\hline 2 & $24.1 \pm 0.8(12)$ & $30.0 \pm 1.6(14)^{* *}$ & $20.5 \pm 0.4(4)^{\dagger}$ & $24.9 \pm 0.9(5)^{* * \wedge}$ & $23.1 \pm 2.0(3)$ & $31.5 \pm 0.8(7)^{*}$ \\
\hline 4 & $26.8 \pm 0.8(18)$ & $31.1 \pm 1.3(19)^{* *}$ & $22.7 \pm 0.8(7)^{\ddagger}$ & $26.7 \pm 1.1(7)^{* * \wedge}$ & $26.6 \pm 0.9(13)$ & $33.0 \pm 0.9(16)^{* * *}$ \\
\hline 6 & $26.3 \pm 0.8(14)$ & $33.8 \pm 1.2(15)^{* * *}$ & $25.5 \pm 0.8(12)$ & $28.4 \pm 0.6(12)^{* * \ddagger}$ & $27.7 \pm 1.2(11)$ & $34.7 \pm 1.2(12)^{* * *}$ \\
\hline 8 & $28.0 \pm 0.9(14)$ & $36.5 \pm 1.0(15)^{* * *}$ & $24.0 \pm 0.3(3)^{\ddagger}$ & $33.0 \pm 1.5(3)^{*}$ & $25.2 \pm 1.7(8)$ & $33.7 \pm 2.3(7)^{*}$ \\
\hline \multicolumn{7}{|c|}{ Glucose (mg/dL) } \\
\hline 2 & $148 \pm 9(12)$ & $190 \pm 10(14)^{* *}$ & $85 \pm 7(4)^{\ddagger}$ & $117 \pm 11(5)^{* \ddagger}$ & $152 \pm 17(3)$ & $168 \pm 19(7)$ \\
\hline 4 & $116 \pm 8(16)$ & $163 \pm 9(17)^{* * *}$ & $82 \pm 14(3)$ & $131 \pm 9(7)^{* \dagger}$ & $144 \pm 8(6)^{\wedge}$ & $184 \pm 13(10)^{*}$ \\
\hline 6 & $139 \pm 9(18)$ & $210 \pm 10(18)^{* * *}$ & $85 \pm 5(10)^{\ddagger}$ & $118 \pm 9(10)^{* * \ddagger}$ & $137 \pm 18(7)$ & $157 \pm 10(7)^{\dagger}$ \\
\hline 8 & $111 \pm 4(11)$ & $182 \pm 4(9)^{* * *}$ & $76 \pm 15(5)$ & $137 \pm 5(5)^{* * \ddagger}$ & $160 \pm 2(3)^{\ddagger}$ & $212 \pm 3(3)^{* * * \ddagger}$ \\
\hline
\end{tabular}

Data are means \pm SE. Weight measurements and glucometry of the tail blood were performed after 2, 4, 6, and 8 weeks of feeding. N's are indicated in parentheses. ${ }^{*} P<0.05,{ }^{* *} P \leq 0.01$, and ${ }^{* * *} P<0.001$ versus chow-fed controls; ${ }^{\wedge} P<0.05,{ }^{\dagger} P \leq 0.01$, and ${ }^{\ddagger} P<0.001$ versus Tie2-GFP.

endothelial populations mostly derived from microvessels. To date, there are no acceptable antibodies to specifically isolate these endothelial subtypes although the differential expression of a few genes has been identified [22].

The heterogeneity of endothelial populations among the different vascular beds suggests that the responses of any one vascular bed may be not be reflective of those of the entire circulatory system. We have previously performed gene expression analyses on the endothelium derived from two vascular beds of Tie2-GFP mice and have identified both the specific and common responses of the large vessel endothelium and the microvasculature to the diabetic state [12]. The transcriptional responses of the macrovascular and microvascular endothelial cells to diabetes differ in both the degree and onset of dysregulation. While some transcripts are commonly regulated among the 2 vascular beds, others are specific to one vascular bed. Therefore, the choice of endothelial population is an important consideration when studying endothelial responses and vascular complications of diabetes.

3.5. Endothelial Isolation by Fluorescence-Activated Cell Sorting. In Tie2-GFP mice, GFP expression is driven by the endothelial promoter for the angiopoietin receptor, Tie2, which is important in angiogenesis and vasculogenesis [23]. Therefore, all endothelial cells of Tie2-GFP mice fluoresce at a peak wavelength of $509 \mathrm{~nm}$ when excited at a wavelength of $488 \mathrm{~nm}$. This allows for endothelial cell isolation by fluorescence-activated cell sorting (FACS).

Fat in tissue digests is highly autofluorescent and is particularly abundant in diabetic models. The identification of $\mathrm{GFP}^{+}$endothelial cells is thus enhanced by double staining for CD31/Platelet endothelial cell adhesion molecule 1 (PECAM1), which does not label fat cells. CD31 is highly expressed by endothelial cells and has long been used as a marker for endothelial cell isolation [24]. However, it is also expressed by leukocytes and therefore, may not be used alone. As shown in Figure 3, all GFP ${ }^{+}$cells also exhibit phycoerythrin-CD31 staining, whereas an additional population exhibits CD31 staining without GFP fluorescence.
$\mathrm{GFP}^{+} / \mathrm{CD} 31^{+}$endothelial cell populations represent approximately $1-2 \%$ of the total population of cells derived from muscle and aortic tissue (Figure 3). Approximately 3,500 endothelial cells may be isolated from one mouse aorta and up to 30,000 cells from the skeletal muscle prep described in this study. We routinely collect at least $10,000 \mathrm{GFP}^{+} / \mathrm{CD} 31^{+}$ cells from each pooled tissue sample for transcriptional analysis.

3.6. Confirmation of Endothelial Identity and Assessment of Monocyte Contamination. The endothelial identity of the sorted cells is confirmed by fluorescence microscopy. After FACS, we see only $\mathrm{GFP}^{+}$endothelial cells and no other contaminating, non-GFP cells (Figure 4(a)). Endothelial identity is further confirmed by functional assays. $\mathrm{GFP}^{+}$cells sorted from the skeletal muscle retain the unique endothelial ability to form tubes when plated on Matrigel (Figure 4(b)). In addition, the sorted cells metabolize acetylated-LDL as demonstrated by Dil fluorescence, a property that is specific to endothelial cells and macrophages (Figure 4(c)).

Tie2-expressing myeloid cells have been reported to account for $2-7 \%$ of human blood mononuclear cells [25], which also express CD1lb. We analyzed the number of $\mathrm{CD} 1 \mathrm{~b}^{+}$events within our sorting gates by flow cytometry of muscle tissue suspensions from 3 independent experiments following 8 weeks of diet. In Tie2-GFP mice, FACS revealed that only $0.8 \pm 0.4 \%$ of $\mathrm{GFP}^{+}$cells derived from HFD animals also display the monocyte marker CD11b with similar low percentages observed in control animals $(0.3 \pm 0.5 \%)$. Similarly, analysis of $\mathrm{GFP}^{+}$cells derived from ScN/GFP mice reveals few $\mathrm{GFP}^{+}$cells staining for $\mathrm{CD} 11 \mathrm{~b}$ in pooled samples from either control or HFD mice (Figure 5).

In diabetes, there exists a state of inflammation characterized by an increase in activated monocytes in the peripheral blood of diabetic patients [26]. Analysis of the CD11b ${ }^{+}$/ $\mathrm{CD}_{115^{+}}$inflammatory monocyte population in peripheral blood reveals a nonsignificant increase from $9 \pm 2 \%$ of $C D 45^{+}$ leukocytes in chow-fed mice to $11 \pm 3 \%$ in Tie2-GFP mice fed HFD for 8 weeks (Table 3). We therefore investigated whether the number of monocytes appearing to have a positive signal 

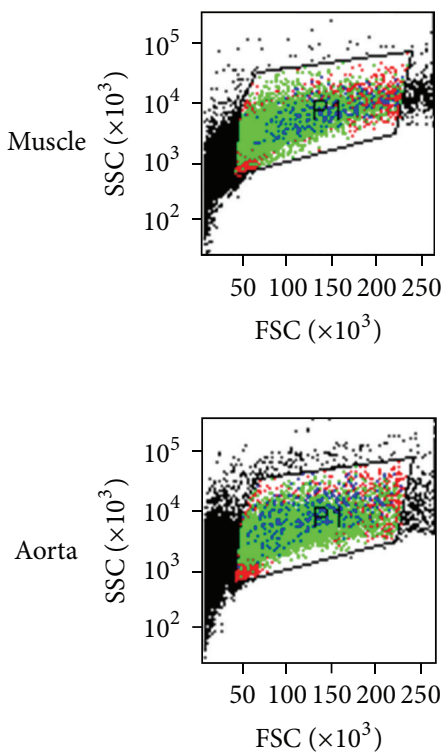
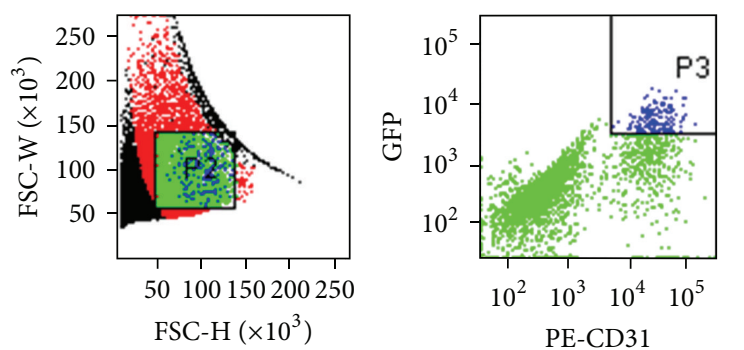

(a)
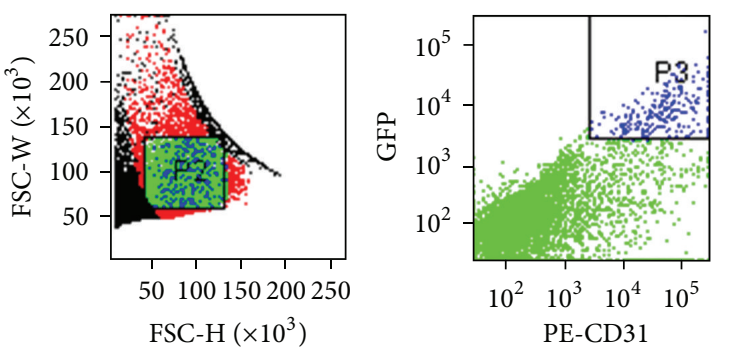

\begin{tabular}{|cccc|}
\hline Population & No. events $\%$ parent & \% total \\
\hline All events & 20,006 & & 100.0 \\
& & \\
P1 & 12,670 & 63.3 & 63.3 \\
P2 & 9,278 & 73.2 & 46.4 \\
P3 & 290 & 3.1 & 1.4 \\
\hline
\end{tabular}

(b)

FIGURE 3: FACS isolation of endothelium. FACS profiles of collagenolytic digests of leg muscle (a) or aorta (b) from ScN/GFP mice. Cell suspensions from ScN/GFP tissues were labeled with phycoerythrin- $\alpha$ CD31. Cells are first gated by size and granularity based on forward and side scatter pulse area (FSC/SSC, gate P1) followed by further selection for mononuclear cells based on forward scatter pulse width and height (FSC-W/FSC-H, gate P2). Cells expressing CD31 and GFP are then gated by phycoerythrin and GFP fluorescent signals as determined based on unstained samples. $\mathrm{GFP}^{+} / \mathrm{CD} 31^{+}$endothelial cells shown in gate P3 are sorted on a FACSAria directly into TRIzol or media for subsequent analysis.

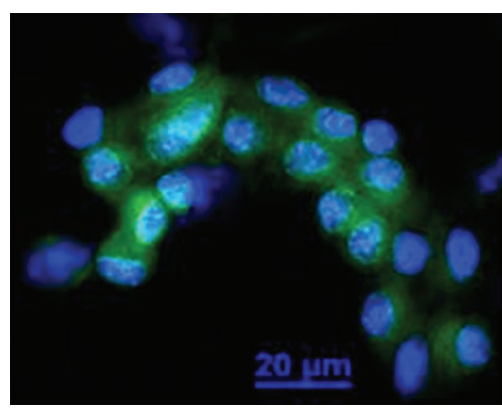

(a)

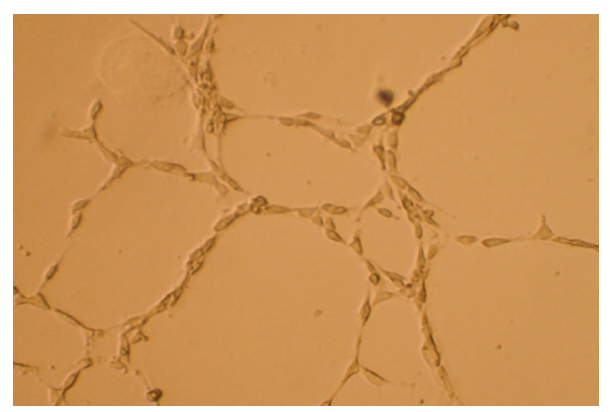

(b)

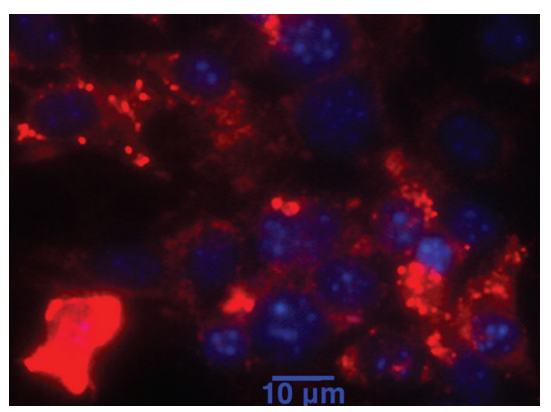

(c)

FIGURE 4: Confirmation of endothelial identity. GFP ${ }^{+}$cells sorted by FACS were collected directly into media. (a) Cells were spun onto slides and fixed for viewing by fluorescence microscopy to confirm the presence of only GFP ${ }^{+}$cells. (b) Sorted cells form tubular structures after 5 days when plated on matrigel. (c) Sorted cells cultured for 5 days take up Dil-Ac-LDL after a $4 \mathrm{~h}$ incubation.

for GFP was altered by HFD. As shown in Table 3, chow and HFD mice display similar, low levels of $\mathrm{GFP}^{+}$cells in the peripheral blood. Importantly, this " $\mathrm{GFP}^{+}$" signal is much lower than that obtained from the endothelial population and would therefore be excluded by gating.

3.7. Sorted Endothelial Cells Are Suited for Gene Expression Analysis. The endothelial cell sorting technique described here is useful for transcriptional studies of endothelial dysfunction where pure populations of endothelial cells are necessary. We have previously analyzed the endothelial response to diabetes in the aortic and muscle endothelium of Tie2GFP mice. Here we have performed similar studies on APOEdeficient mice in order to determine the effect of preexisting hypercholesterolemia on the endothelial response to diabetes. While Tie2-GFP mice have 209 transcripts dysregulated $>2$ fold in the aortic endothelium by 4 weeks of HFD compared to chow-fed controls, ApoE(-/-)/GFP mice on HFD have only 32 transcripts dysregulated to this degree compared to chow-fed $A p o E(-/-) / G F P$ controls. Thus, the endothelial response to the diabetic milieu is blunted in $A p o E(-/-) / G F P$ mice, most likely due to preexisting endothelial activation in the hypercholesterolemic state. However, some transcripts, such as vascular cell adhesion molecule 1 (VCAM-1) and insulin-like growth factor II (Igf-II), are differentially regulated in $A p o E(-/-) / G F P$ mice after HFD compared to chow-fed controls. Transcripts dysregulated in the aortic endothelium are shown in Table 4(a) and those dysregulated 

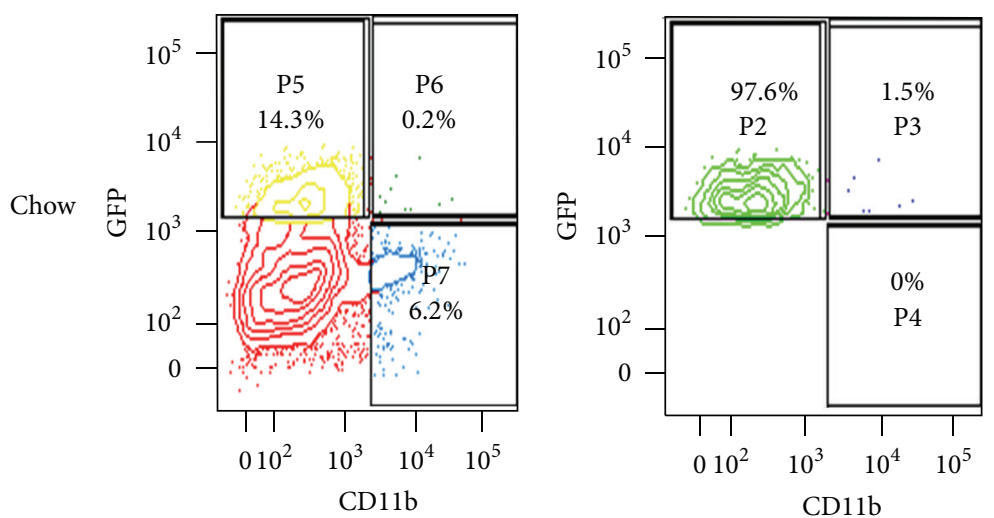

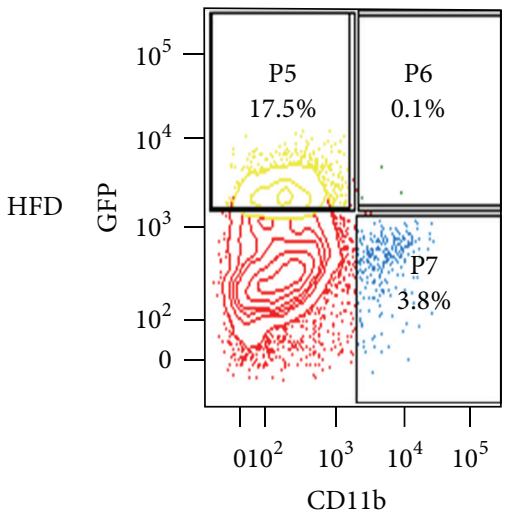

(a)

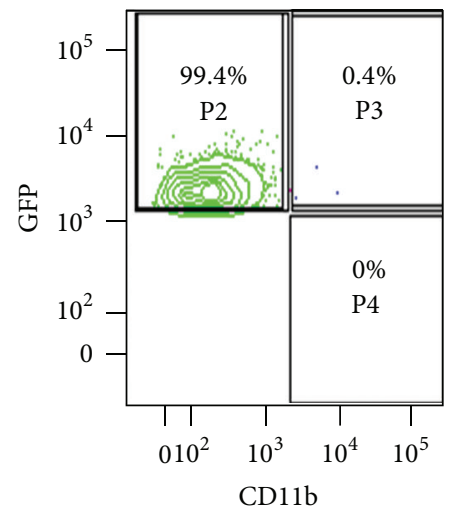

(b)

FIGURE 5: Flow cytometry analysis of monocyte marker expression in the sorted endothelial population. Cells from the skeletal muscle of ScN/GFP mice fed chow or HFD for 8 weeks were stained for the monocyte marker CD11b. (a) Percentage of all mononuclear cells that are $\mathrm{GFP}^{+} / \mathrm{CD}_{11 b}{ }^{-}, \mathrm{GFP}^{+} / \mathrm{CD}_{11 b^{+}}$, or $\mathrm{GFP}^{-} / \mathrm{CD}_{11 b^{+}}$are shown in gates $\mathrm{P} 5-\mathrm{P}$, respectively. (b) Percentage of the sorting population that are $\mathrm{GFP}^{+} / \mathrm{CD}_{11 b}{ }^{-}$or $\mathrm{GFP}^{+} / \mathrm{CD} 1 b^{+}$are indicated in gates $\mathrm{P} 2$ and $\mathrm{P} 3$. The sorting gate is established based on $\mathrm{GFP}^{+}$fluorescent signal above non-GFP sample. There are no $\mathrm{GFP}^{-} / \mathrm{CD} 1 \mathrm{~b}^{+}$cells within the sorting gate as shown in gate $\mathrm{P} 4$. Only $\mathrm{GFP}^{+}$cells with no fluorescent signal for CD11b are present in unstained samples from ScN/GFP mice (not shown).

TABLE 3: Flow cytometry analysis of Tie2-GFP expression in peripheral blood mononuclear cells (PBMCs) derived from Tie2-GFP mice fed a high-fat or chow diet for 8 weeks.

\begin{tabular}{|c|c|c|c|c|}
\hline & $\mathrm{CD} 11 \mathrm{~b}^{+}\left(\%\right.$ of $\left.\mathrm{CD} 45^{+}\right)$ & $\mathrm{CD} 11 \mathrm{~b}^{+} / \mathrm{CD} 115^{+}\left(\%\right.$ of $\left.\mathrm{CD} 45^{+}\right)$ & $\mathrm{GFP}^{+}\left(\%\right.$ of $\left.\mathrm{CD} 45^{+} / \mathrm{CD} 11 \mathrm{~b}^{+}\right)$ & $\mathrm{GFP}^{+}\left(\%\right.$ of $\left.\mathrm{CD} 45^{+} / \mathrm{CD} 1 b^{+} / \mathrm{CD} 115^{+}\right)$ \\
\hline Chow & $30 \pm 4$ & $9 \pm 2$ & $0.6 \pm 0.1$ & $0.8 \pm 0.3$ \\
\hline HFD & $33 \pm 6$ & $11 \pm 3$ & $0.6 \pm 0.2$ & $0.8 \pm 0.5$ \\
\hline
\end{tabular}

PBMCs were isolated and stained for CD45, CD11b, and CD115. The population positive for the common leukocyte antigen, CD 45, was analyzed for CD11b ${ }^{+}$ myeloid cells and $\mathrm{CD}_{11 b^{+}} / \mathrm{CD}_{115}{ }^{+}$monocytes. The percentage of these populations appearing to have a positive signal for GFP is shown. Data is presented as mean $\pm \operatorname{SD}(n=3)$.

in the skeletal muscle are presented in Table 4(b). Similar transcriptional analyses may be performed on ScN/GFP mice to elucidate the role of TLR4 in vascular insulin resistance and endothelial dysfunction upon high-fat feeding.

3.8. Potential Limitations. The use of the Tie2-GFP transgene, which is expressed at moderately high levels, may potentially affect endothelial function, either by nonspecific effects of a novel protein or, perhaps, by specific squelching effects of the Tie 2 promoter on expression of the endogenous Tie 2 gene. We have not seen any gross effects upon the phenotyping described in this study; however, we cannot exclude subtle effects. It is thus ultimately useful to confirm results from the Tie2-GFP studies in nontransgenic models. For example, transcriptional regulation identified in FACS-sorted cells can be confirmed by immunohistology or in situ hybridization on nontransgenic vascular samples.

\section{Conclusions}

We have demonstrated the feasibility of isolating vascular endothelial cells from murine models of diabetes in order to study responses of the diabetic vasculature. We have shown that the endothelium may be isolated from these 
TABLE 4: (a) Transcripts dysregulated $<-0.75$ or $>0.75 \log _{2}$ fold in the aortic endothelium of ApoE(-/-)/GFP mice after 4 weeks of high-fat diet versus chow diet. (b) Transcripts dysregulated $<-0.75$ or $>0.75 \log _{2}$ fold in the skeletal muscle endothelium of ApoE(-/-)/GFP mice after 4 weeks of high-fat diet versus chow diet.

(a)

\begin{tabular}{|c|c|c|c|c|}
\hline RefSeq & Description & Gene symbol & $\log _{2}$ fold change & $P$ value \\
\hline NM_008134 & Glycosylation-dependent cell adhesion molecule 1 & Glycam1 & 2.539 & 0.01 \\
\hline NM_010382 & Histocompatibility 2, class II antigen E beta & $\mathrm{H} 2-\mathrm{Eb} 1$ & 2.22 & 0.01 \\
\hline NM_011498 & Basic helix-loop-helix domain containing, class B2 & Bhlhb2 & 1.388 & 0.05 \\
\hline NM_011693 & Vascular cell adhesion molecule 1 & Vcaml & 1.377 & 0.03 \\
\hline NM_019414 & Selenium-binding protein 2 & Selenbp 2 & 1.228 & 0.04 \\
\hline NM_007929 & Epithelial membrane protein 2 & Emp2 & 1.211 & 0.02 \\
\hline NM_013904 & Hairy/enhancer-of-split-related with YRPW motif 2 & Hey2 & 1.188 & 0.05 \\
\hline NM_023117 & Cell division cycle 25 homolog B (S. cerevisiae) & Cdc25b & 1.164 & 0.04 \\
\hline NM_145144 & RIKEN cDNA 2810003C17 gene & 2810003C17Rik & 1.112 & 0.02 \\
\hline XM_128002 & Collagen triple helix repeat containing 1 & Cthrcl & 1.095 & 0.01 \\
\hline NM_007554 & Bone morphogenetic protein 4 & Bmp4 & 1.082 & 0.01 \\
\hline NM_175397 & RIKEN cDNA 5830484A20 gene & 5830484A20Rik & 1.042 & 0.02 \\
\hline XM_484254 & Extracellular matrix protein 2 & $\mathrm{Ecm} 2$ & 1.032 & 0.03 \\
\hline NM_008357 & Interleukin 15 , transcript variant 1, mRNA & $\mathrm{Il15}$ & 0.993 & 0.05 \\
\hline NM_022004 & FXYD domain-containing ion transport regulator 6 & Fxyd6 & 0.976 & 0.03 \\
\hline XM_133801 & $\begin{array}{l}\text { Golgi associated, gamma adapt-in ear containing, } \\
\text { ARF-binding protein } 2\end{array}$ & Gga2 & 0.933 & 0.03 \\
\hline NM_138587 & Family with sequence similarity 3 , member C & fam $3 c$ & 0.924 & 0.04 \\
\hline NM_025809 & C-type lectin domain family 14 , member a & Clec14a & 0.911 & 0.02 \\
\hline NM_013750 & Pleckstrin homology-like domain, family A, member 3 & Phlda3 & 0.899 & 0.03 \\
\hline NM_008330 & Interferon gamma inducible protein 47 & Ifi47 & 0.892 & 0.04 \\
\hline XM_140320 & Coiled-coil domain containing 112 & Ccdc112 & 0.879 & 0.03 \\
\hline NM_133663 & Integrin beta 4 & Itgb4 & 0.879 & 0.02 \\
\hline NM_025443 & Partner of NOB1 homolog (S. cerevisiae) & Pnol & 0.875 & 0.03 \\
\hline NM_007722 & Chemokine (C-X-C motif) receptor 7 & Cxcr7 & 0.875 & 0.01 \\
\hline XM_485110 & RIKEN cDNA $2210418 \mathrm{O} 10$ gene & 2210418O10Rik & 0.87 & 0.02 \\
\hline NM_009463 & Uncoupling protein 1 (mitochondrial, proton carrier) & Ucpl & 0.857 & 0.04 \\
\hline NM_177618 & cDNA sequence BC030477 & BC030477 & 0.856 & 0.02 \\
\hline NM_183259 & RIKEN cDNA 2210020M01 gene & 2210020M01Rik & 0.83 & 0.02 \\
\hline NM_010514 & Insulin-like growth factor 2 & Igf2 & 0.819 & 0.04 \\
\hline NM_010424 & Hemochromatosis & Hfe & 0.815 & 0.03 \\
\hline NM_177325 & TSR1, 20S rRNA accumulation, homolog (yeast) & Tsrl & 0.814 & 0.02 \\
\hline NM_001004062 & CREB-regulated transcription coactivator 1 & Crtcl & 0.802 & 0.01 \\
\hline NM_133964 & Deoxyhypusine hydroxylase/monooxygenase & Dohh & 0.797 & 0.00 \\
\hline NM_212445 & KDEL (Lys-Asp-Glu-Leu) containing 2 & Kdelc2 & 0.795 & 0.03 \\
\hline NM_027334 & UbiE-YGHL1 fusion protein & Ubie & 0.768 & 0.02 \\
\hline NM_008610 & Matrix metallopeptidase 2 & Mmp2 & 0.765 & 0.03 \\
\hline NM_009024 & Retinoic acid receptor, alpha & Rara & 0.759 & 0.04 \\
\hline NM_008659 & Myosin IC & Myolc & -0.818 & 0.00 \\
\hline NM_001002239 & Ribosomal protein L17, mRNA & Rpl17 & -0.85 & 0.02 \\
\hline NM_146011 & Rho GTPase activating protein 9 & Arhgap9 & -0.872 & 0.01 \\
\hline NM_020261 & Pregnancy-specific glycoprotein 23 & Psg23 & -0.874 & 0.01 \\
\hline NM_016892 & Copper chaperone for superoxide dismutase & Ccs & -0.905 & 0.02 \\
\hline
\end{tabular}


(a) Continued.

\begin{tabular}{llccc}
\hline RefSeq & Description & Gene symbol & $\log _{2}$ fold change & $P$ value \\
\hline NM_021469 & Dysferlin & Dysf & -0.943 \\
NM_027015 & Ribosomal protein S27 & Rps27 & -1.174 \\
NM_010826 & MRV integration site 1 & Mrvil & -1.218 \\
NM_007913 & Early growth response 1 & Egr1 & -1.423 \\
NM_017398 & Diaphanous homolog 2 (Drosophila) & Diap2 & -1.485 \\
\hline
\end{tabular}

(b)

\begin{tabular}{|c|c|c|c|c|}
\hline RefSeq & Description & Gene symbol & $\log _{2}$ fold change & $P$ value \\
\hline NM_025557 & Purkinje cell protein 4 -like 1 & Pcp4l1 & 1.988 & 0.01 \\
\hline NM_008250 & H2.0-like homeo box 1 (Drosophila) & Hlx1 & 1.544 & 0.05 \\
\hline NM_013549 & Histone cluster 2, $\mathrm{H} 3 \mathrm{c} 2$ & Hist $2 \mathrm{~h} 3 \mathrm{c} 2$ & 1.536 & 0.01 \\
\hline NM_011620 & Troponin T3, skeletal, fast & Tnnt3 & 1.426 & 0.04 \\
\hline NM_029688 & Sulfiredoxin 1 homolog (S. cerevisiae) & Srxnl & 1.335 & 0.03 \\
\hline NM_026095 & Small nuclear ribonucleoprotein D3 & Snrpd3 & 1.277 & 0.04 \\
\hline NM_010382 & Histocompatibility 2, class II antigen E beta & $\mathrm{H} 2-\mathrm{Eb} 1$ & 1.264 & 0.02 \\
\hline NM_008162 & Glutathione peroxidase 4 & Gpx4 & 1.221 & 0.02 \\
\hline XM_488375 & $\begin{array}{l}\text { Similar to barrier to autointegration factor } 1 \\
\text { (LOC385407) }\end{array}$ & - & 1.215 & 0.02 \\
\hline NM_007507 & $\begin{array}{l}\text { ATP synthase, } \mathrm{H}+\text { transporting, mitochondrial F1F0 } \\
\text { complex, subunit e }\end{array}$ & Atp5k & 1.199 & 0.01 \\
\hline NM_011313 & S100 calcium-binding protein A6 (calcyclin) & S100a6 & 1.197 & 0.02 \\
\hline XM_128110 & Polymerase (RNA) II (DNA directed) polypeptide F & Polr2f & 1.195 & 0.00 \\
\hline NM_207648 & Histocompatibility 2, Q region locus 6 & H2-Q6 & 1.176 & 0.01 \\
\hline NM_010361 & Glutathione S-transferase, theta 2 & Gstt2 & 1.166 & 0.01 \\
\hline NM_181316 & RIKEN cDNA E130103I17 gene & E130103I17Rik & 1.136 & 0.03 \\
\hline NM_011119 & Proliferation-associated 2G4 & $\mathrm{Pa} 2 \mathrm{~g} 4$ & 1.119 & 0.03 \\
\hline NM_153152 & RIKEN cDNA 2410015M20 gene & 2410015M20Rik & 1.086 & 0.01 \\
\hline NM_053078 & $\begin{array}{l}\text { DNA segment, human D4S114 (D0H4S114), transcript } \\
\text { variant } 1\end{array}$ & - & 1.065 & 0.04 \\
\hline NM_013706 & CD52 antigen & Cd52 & 1.047 & 0.02 \\
\hline NM_026616 & Ribonuclease $\mathrm{H} 2$, subunit $\mathrm{C}$ & Rnaseh2c & 1.044 & 0.01 \\
\hline NM_011289 & Ribosomal protein L27 & Rpl27 & 1.02 & 0.01 \\
\hline XM_109683 & RIKEN cDNA $1810027 \mathrm{O} 10$ gene & 1810027O10Rik & 1.006 & 0.02 \\
\hline NM_018832 & PDZ domain containing, $\mathrm{X}$ chromosome & Pdzx & 1.003 & 0.02 \\
\hline NM_024171 & Sec61 beta subunit & Sec6lb & 0.95 & 0.02 \\
\hline NM_009081 & Ribosomal protein L28 & Rpl28 & 0.95 & 0.04 \\
\hline NM_008210 & $\mathrm{H} 3$ histone, family $3 \mathrm{~A}$ & H3f3a & 0.942 & 0.02 \\
\hline XM_193800 & RIKEN cDNA 1500032L24 gene & 1500032L24Rik & 0.927 & 0.01 \\
\hline XM_489638 & Ribosomal protein L26 & Rpl26 & 0.91 & 0.04 \\
\hline NM_021407 & Triggering receptor expressed on myeloid cells 3 & Trem3 & 0.872 & 0.02 \\
\hline NM_009811 & Caspase 6 & Casp6 & 0.858 & 0.04 \\
\hline NM_011185 & Proteasome (prosome, macropain) subunit, beta type 1 & Psmb1 & 0.855 & 0.01 \\
\hline NM_008303 & Heat shock protein 1 (chaperonin 10 ), related sequence 1 & Hspe1-rs1 & 0.84 & 0.00 \\
\hline NM_019682 & Dynein light chain LC8-type 1 & Dynll1 & 0.836 & 0.04 \\
\hline XM_138368 & Similar to Rpl7a protein (LOC217924) & - & 0.816 & 0.02 \\
\hline NM_010174 & Fatty-acid-binding protein 3 , muscle and heart & Fabp3 & 0.813 & 0.03 \\
\hline NM_175399 & Exosome component 4 & Exosc4 & 0.81 & 0.04 \\
\hline
\end{tabular}


(b) Continued.

\begin{tabular}{llccc}
\hline RefSeq & Description & Gene symbol & $\log _{2}$ fold change & $P$ value \\
\hline NM_013498 & Camp-responsive element modulator & Crem & 0.802 & 0.00 \\
NM_010394 & Histocompatibility 2, Q region locus 7 & H2-Q7 & 0.793 & 0.03 \\
NM_011129 & Septin 4 & 39329 & 0.785 & 0.04 \\
NM_025396 & 6-Phosphogluconolactonase & Pgls & 0.783 & 0.05 \\
NM_212470 & RIKEN cDNA 0610007C21 gene & 0610007C21Rik & 0.779 & 0.02 \\
XM_133877 & RIKEN cDNA 4933402N03 gene & 4933402N03Rik & 0.774 & 0.02 \\
NM_011343 & SEC61, gamma subunit & Sec61g & 0.77 & 0.02 \\
NM_025946 & RIKEN cDNA 2010100O12 gene & 2010100O12Rik & 0.767 & 0.05 \\
NM_025338 & Aurora kinase A interacting protein 1 & Aurkaipl & 0.761 & 0.01 \\
NM_009077 & Ribosomal protein L18 & Rpl18 & 0.753 & 0.05 \\
\hline
\end{tabular}

mice by FACS of $\mathrm{GFP}^{+} / \mathrm{CD} 31^{+}$cells. Flow cytometry analyses, fluorescence microscopy, and functional studies have shown the sorted cells to be pure populations of endothelial cells with minimal contamination by other cell types. This sorting technique may be applied to isolate the endothelium of any strain interbred with Tie2-GFP mice.

In this study, we describe the metabolic responses and endothelial isolation of ScN/GFP and ApoE(-/-)/GFP mice. ScN/GFP mice display decreased susceptibility to the development of insulin resistance by HFD as demonstrated by lower fasting glucose and insulin levels and improved glucose tolerance compared to Tie2-GFP mice. TLR4 has been shown to play a role in vascular insulin resistance due to its ability to bind free fatty acids and activate inflammatory pathways [14]. Therefore, this model of high-fat feeding and endothelial isolation may be useful to explore the metabolic and vascular changes due to TLR4 deficiency. ApoE(-/-)/GFP mice display elevated glucose and cholesterol levels compared to Tie2-GFP mice. Transcriptional analyses of the endothelium isolated from the aorta and skeletal muscle of these mice demonstrate reduced endothelial response to HFD, perhaps resulting from endothelial dysfunction in the preexisting hypercholesterolemic state in chow-fed ApoE(-/-)/GFP mice. Similar studies to evaluate the effect of gene loss on the diabetic endothelium and vascular responses may be performed by utilizing the techniques described in this study.

\section{Conflict of Interests}

No conflict of interests (financial or otherwise) have been declared by the authors.

\section{Acknowledgments}

This work was supported by National Institutes of Health Grants 5P20RR016453 and 5UH1HL-073449 to R. V. Shohet, Hawaii Community Foundation Grant 20061485 to J. G. Maresh, and American Heart Association Predoctoral Award 11PRE7720065 to A. L. Darrow. The authors thank Alexandra Gurary of the Molecular and Cellular Immunology Core Facility supported by RCMI (5 G12 RR003061-25) and COBRE (P20RR018727) Grants for assistance with FACS and
Y. vonne Baumer for her help with endothelial functional assays.

\section{References}

[1] Centers for Disease Control and Prevention, National Diabetes Fact Sheet: National Estimates and General Information on Diabetes and Prediabetes in the United States, 2011, Department of Health and Human Services, Centers for Disease Control and Prevention, Atlanta, Ga, USA, 2011.

[2] J. Xu and M. H. Zou, "Molecular insights and therapeutic targets for diabetic endothelial dysfunction," Circulation, vol. 120, no. 13, pp. 1266-1286, 2009.

[3] R. Nagai, Y. Unno, M. C. Hayashi et al., "Peroxynitrite induces formation of $\mathrm{N} \varepsilon$-(carboxymethyl)lysine by the cleavage of Amadori product and generation of glucosone and glyoxal from glucose: novel pathways for protein modification by peroxynitrite," Diabetes, vol. 51, no. 9, pp. 2833-2839, 2002.

[4] P. Pacher and C. Szabó, "Role of peroxynitrite in the pathogenesis of cardiovascular complications of diabetes," Current Opinion in Pharmacology, vol. 6, no. 2, pp. 136-141, 2006.

[5] M. H. Zou, R. A. Cohen, and V. Ullrich, "Peroxynitrite and vascular endothelial dysfunction in diabetes mellitus," Endothelium, vol. 11, no. 2, pp. 89-97, 2004.

[6] S. D. Funk, A. Yurdagul Jr., and A. W. Orr, "Hyperglycemia and endothelial dysfunction in atherosclerosis: lessons from type 1 diabetes," International Journal of Vascular Medicine, vol. 2012, Article ID 569654, 19 pages, 2012.

[7] J. S. Pober and W. C. Sessa, "Evolving functions of endothelial cells in inflammation," Nature Reviews Immunology, vol. 7, no. 10, pp. 803-815, 2007.

[8] C. A. Simmons, J. Zilberberg, and P. F. Davies, "A rapid, reliable method to isolate high quality endothelial RNA from small spatially-defined locations," Annals of Biomedical Engineering, vol. 32, no. 10, pp. 1453-1459, 2004.

[9] M. Civelek, E. Manduchi, R. J. Riley, C. J. Stoeckert Jr., and P. F. Davies, "Chronic endoplasmic reticulum stress activates unfolded protein response in arterial endothelium in regions of susceptibility to atherosclerosis," Circulation Research, vol. 105, no. 5, pp. 453-461, 2009.

[10] N. T. Luu, M. Rahman, P. C. Stone, G. E. Rainger, and G. B. Nash, "Responses of endothelial cells from different vessels to inflammatory cytokines and shear stress: evidence for the pliability of endothelial phenotype," Journal of Vascular Research, vol. 47, no. 5, pp. 451-461, 2010. 
[11] F. M. Marelli-Berg, E. Peek, E. A. Lidington, H. J. Stauss, and R. I. Lechler, "Isolation of endothelial cells from murine tissue," Journal of Immunological Methods, vol. 244, no. 1-2, pp. 205-215, 2000.

[12] A. L. Darrow, R. V. Shohet, and J. G. Maresh, "Transcriptional analysis of the endothelial response to diabetes reveals a role for galectin-3," Physiological Genomics, vol. 43, pp. 1144-1152, 2011.

[13] J. A. Thomas, M. F. Tsen, D. J. White, and J. W. Horton, "TLR4 inactivation and rBPI21 block burn-induced myocardial contractile dysfunction," American Journal of Physiology, vol. 283, no. 4, pp. H1645-H1655, 2002.

[14] F. Kim, M. Pham, I. Luttrell et al., "Toll-like receptor-4 mediates vascular inflammation and insulin resistance in diet-induced obesity," Circulation Research, vol. 100, no. 11, pp. 1589-1596, 2007.

[15] R. S. Surwit, M. N. Feinglos, J. Rodin et al., "Differential effects of fat and sucrose on the development of obesity and diabetes in C57BL/6J and A/J mice," Metabolism, vol. 44, no. 5, pp. 645-651, 1995.

[16] A. E. Petro, J. Cotter, D. A. Cooper, J. C. Peters, S. J. Surwit, and R. S. Surwit, "Fat, carbohydrate, and calories in the development of diabetes and obesity in the C57BL/6J mouse," Metabolism, vol. 53, no. 4, pp. 454-457, 2004.

[17] A. Astrup, B. Buemann, P. Western, S. Toubro, A. Raben, and N. J. Christensen, "Obesity as an adaptation to a high-fat diet: evidence from a cross- sectional study," American Journal of Clinical Nutrition, vol. 59, no. 2, pp. 350-355, 1994.

[18] J. C. Lovejoy, M. M. Windhauser, J. C. Rood, and J. A. de la Bretonne, "Effect of a controlled high-fat versus low-fat diet on insulin sensitivity and leptin levels in African-American and Caucasian women," Metabolism, vol. 47, no. 12, pp. 1520-1524, 1998.

[19] J. A. Marshall, S. Hoag, S. Shetterly, and R. F. Hamman, "Dietary fat predicts conversion from impaired glucose tolerance to NIDDM: the San Luis Valley Diabetes Study," Diabetes Care, vol. 17, no. 1, pp. 50-55, 1994.

[20] V. Guay, B. Lamarche, A. Charest, A. J. Tremblay, and P. Couture, "Effect of short-term low- and high-fat diets on low-density lipoprotein particle size in normolipidemic subjects," Metabolism, vol. 61, pp. 76-83, 2012.

[21] S. M. Reyna, S. Ghosh, P. Tantiwong et al., "Elevated toll-like receptor 4 expression and signaling in muscle from insulinresistant subjects," Diabetes, vol. 57, no. 10, pp. 2595-2602, 2008.

[22] N. Ieronimakis, G. Balasundaram, and M. Reyes, "Direct isolation, culture and transplant of mouse skeletal muscle derived endothelial cells with angiogenic potential," PLoS One, vol. 3, no. 3, Article ID e0001753, 2008.

[23] T. Motoike, S. Loughna, E. Perens et al., "Universal GFP reporter for the study of vascular development," Genesis, vol. 28, pp. 7581, 2000.

[24] A. Vecchi, C. Garlanda, M. G. Lampugnani et al., "Monoclonal antibodies specific for endothelial cells of mouse blood vessels: their application in the identification of adult and embryonic endothelium," European Journal of Cell Biology, vol. 63, no. 2, pp. 247-254, 1994.

[25] M. A. Venneri, M. de Palma, M. Ponzoni et al., "Identification of proangiogenic TIE2-expressing monocytes (TEMs) in human peripheral blood and cancer," Blood, vol. 109, no. 12, pp. 52765285, 2007.

[26] K. Mastej and R. Adamiec, "Role of polymorphonuclear leukocytes in development vascular complications in diabetes," Polski Merkuriusz Lekarski, vol. 20, no. 115, pp. 36-40, 2006. 


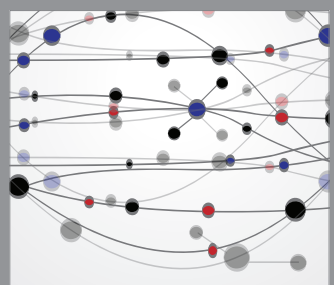

The Scientific World Journal
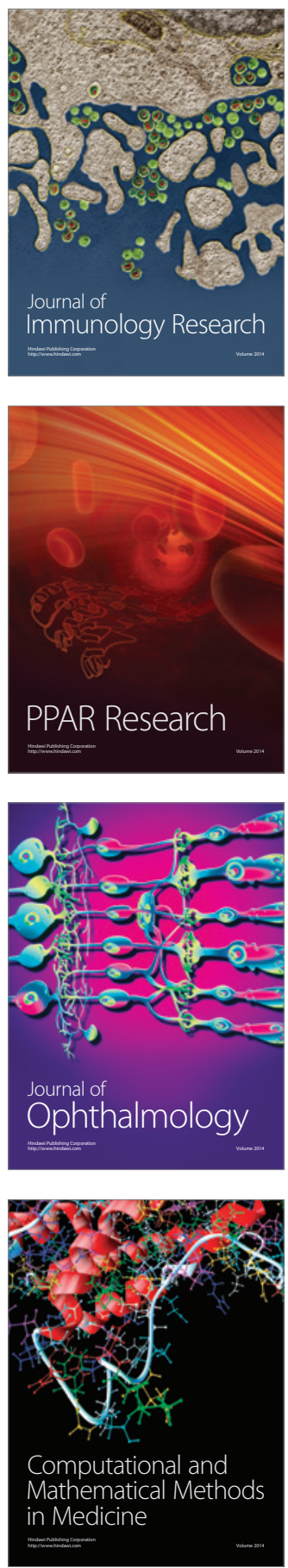

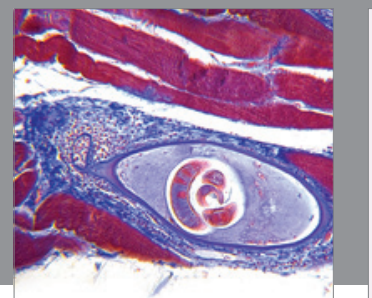

Gastroenterology

Research and Practice
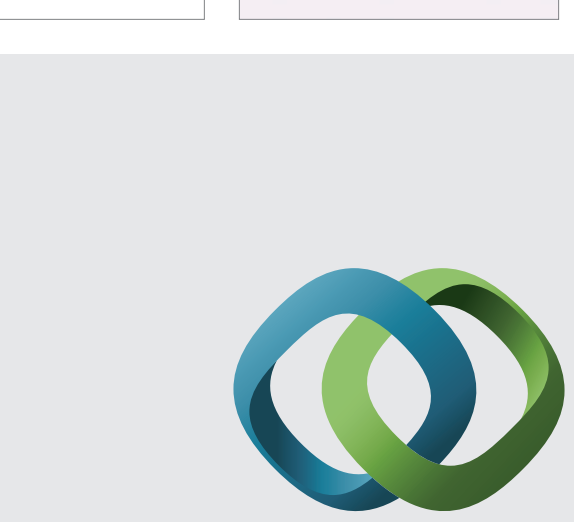

\section{Hindawi}

Submit your manuscripts at

http://www.hindawi.com
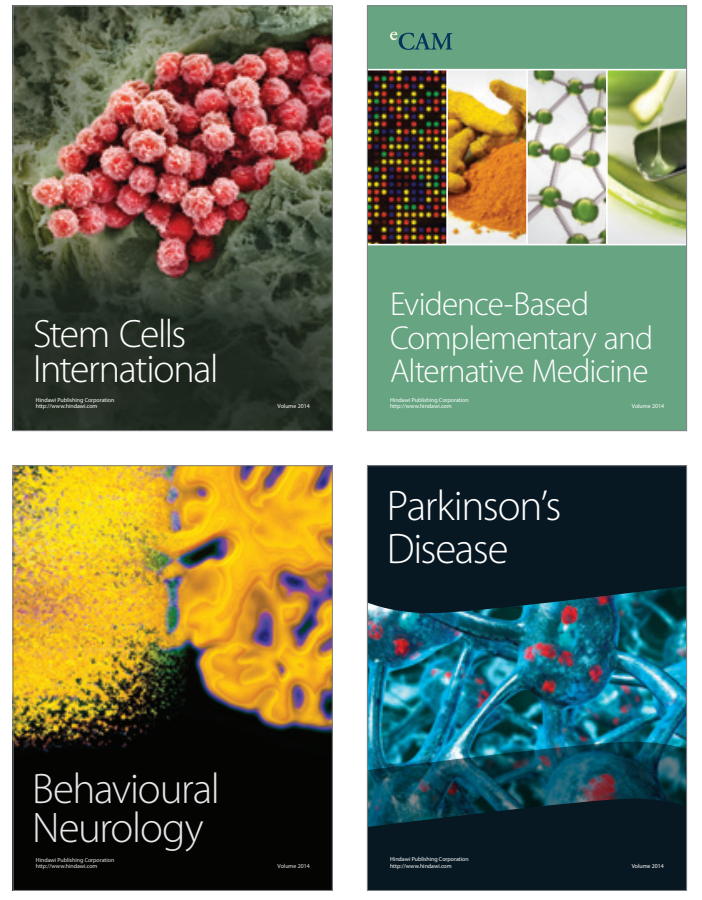
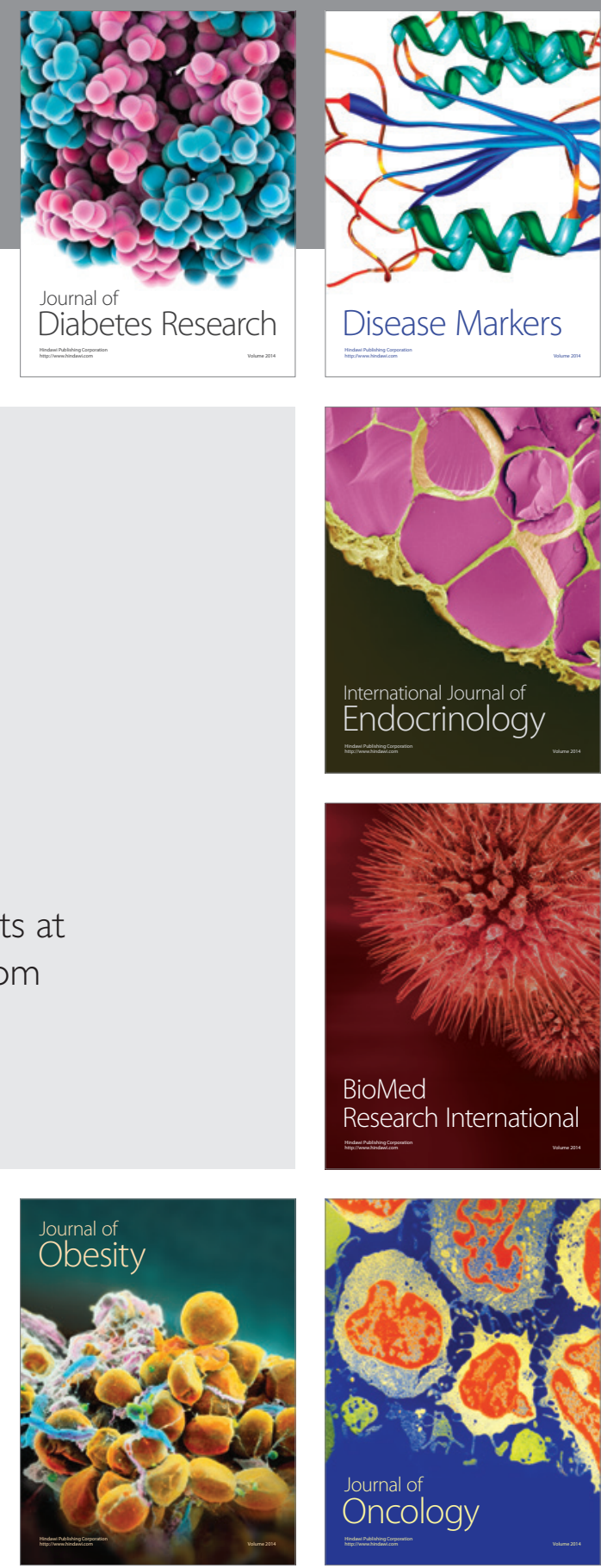

Disease Markers
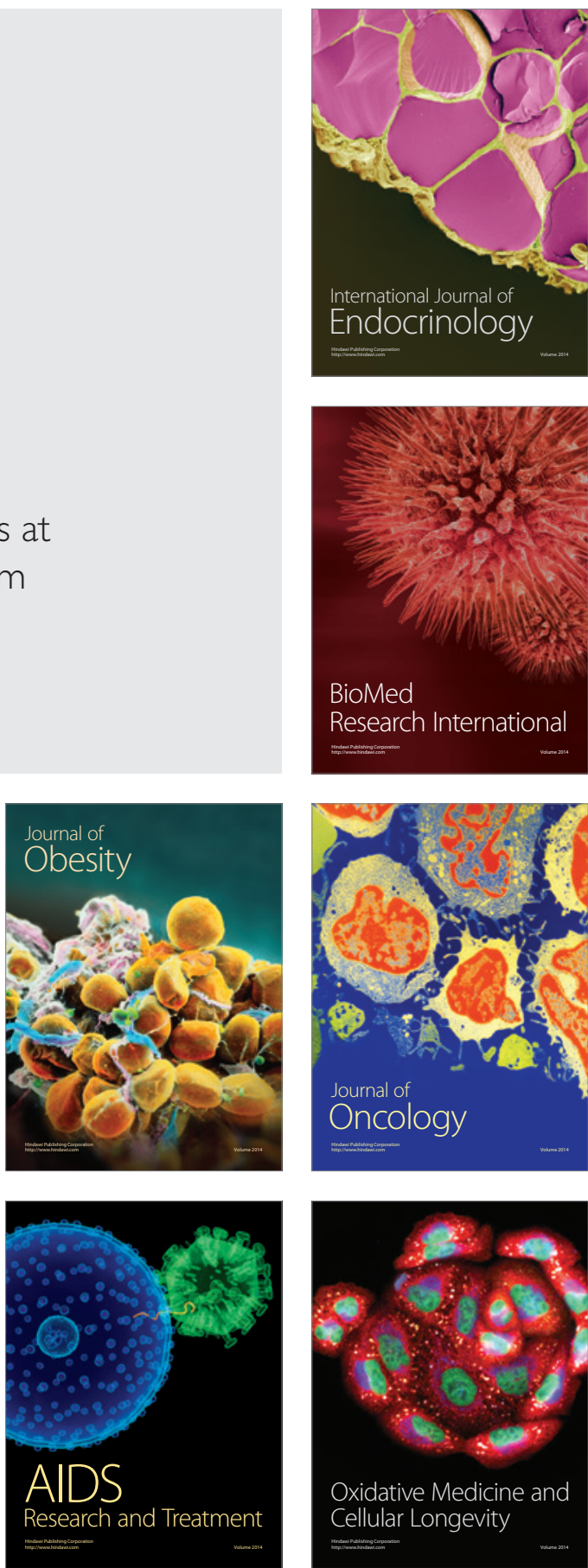